Article

\title{
Registros de Queimadas em Vegetação (Incêndios) e a Climatologia da Chuvas no Estado do Ceará: Estudo de Caso no Período de 2015 a 2019
}

\author{
Emerson Mariano da Silva ${ }^{1}$ (D), Henrique Cesar Monteiro Carvalho ${ }^{1,2}$, \\ Lindenberg Lucena da Silva ${ }^{3}$, Wellington Antônio Barbosa ${ }^{3}$ \\ ${ }^{1}$ Mestrado Profissional em Climatologia e Aplicações nos Países da CPLP e África, Universidade \\ Estadual do Ceará, Fortaleza, CE, Brasil. \\ ${ }^{2}$ Corpo de Bombeiros Militar do Ceará, Fortaleza, CE, Brasil. \\ ${ }^{3}$ Agência Executiva de Gestão da Águas da Paraíba, Campina Grande, PB, Brasil.
}

Recebido em: 19 de Maio de 2021 - Aceito em: 14 de Junho de 2021

\begin{abstract}
Resumo
Apresenta-se aqui um estudo sobre a relação entre as ocorrências de incêndios em vegetação e a climatologia das chuvas no Ceará. Foram usados registros das ocorrências desses eventos da Coordenadoria Integrada de Operações de Segurança (CIOPS) e os registros climatológicos da Fundação Cearense de Meteorologia e Recursos Hídricos (FUNCEME). Os resultados mostraram que existe uma relação entre a ocorrência de incêndios florestais, associados a prática de atear fogo na vegetação de forma não controlada, e as condições meteorológicas, ambientais e culturais das comunidades cearenses e que o período de estiagem (seco) é o período de maior ocorrência desses registros na região.
\end{abstract}

Palavras-chave: climatologia, queimadas, vegetação.

\section{Records of Vegetation Fires and Rainfall Climatology in the State of Ceará: Case Study from 2015 to 2019}

\begin{abstract}
A study is presented here about the relationship between the occurrence of fires in vegetation and the climatology of the rains in Ceará. Records of the occurrences of these events from the Integrated Coordination of Security Operations (CIOPS) and the climatological records of the Cearense Meteorology and Water Resources Foundation (FUNCEME). The results showed that there is a relationship between the occurrence of forest fires, associated with the practice of setting fire to vegetation in an uncontrolled way, and the meteorological, environmental and cultural conditions of the communities of Ceará and that the dry season (dry season) is the period occurrence of these records in the region.
\end{abstract}

Keywords: climatology, fires, vegetation.

\section{Introdução}

As queimadas ou incêndios em vegetação podem provocar grandes prejuízos ao meio ambiente, como por exemplo, danos à fauna e à flora, aos seres humanos, inclusive com perdas de vidas, além de consequências econômicas consideráveis, bem como a destruição de hábitats, e a queima de madeira, além dos prejuízos com os custos financeiros para o controle dos incêndios e a reconstrução quando necessária (Soares, 1995; Fiedler et al., 2006).

Em adição, encontra-se na literatura reflexões sobre o assunto afirmando que o fogo fora de controle, essencialmente em unidades de conservação, é um importante mecanismo de extermínio da biodiversidade e de interrupção dos processos ecológicos na natureza (Medeiros e Fiedler, 2004; Prudente, 2010).

Autor de correspondência: Emerson Mariano da Silva. E-mail: emerson.mariano@uece.br. 
Segundo Torres e Ribeiro (2008), a maior parte dos incêndios tem origem humana, principalmente os provocados intencionalmente, por desinformação ou motivos passionais. Assim, apesar de anos de estudos científicos e de toda a atenção da imprensa dada as ocorrências de incêndios em vegetação, os efeitos que causam ao meio ambiente ainda têm sido ignorados (Silva et al., 2003).

De acordo com Macedo e Sardinha (1985), a determinação do período mais propício aos incêndios constitui importante ferramenta para a diminuição de prejuízos, riscos e custos em seu combate, visto que permite ações de caráter preventivo pelas entidades responsáveis. Contudo, conhecendo-se o período de maior concentração das ocorrências desonera o trabalho de levantamento dos dados, aumenta sua eficiência e a caracterização do perfil dos incêndios.

Assim, considerado a afirmativa de Prado (2003), que a vegetação da Caatinga existente na região semiárida do nordeste brasileiro é um dos biomas mais afetados por incêndios e que $95 \%$ dos municípios cearenses estão inseridos nessa região (Fig. 1). O objetivo desse trabalho é analisar as ocorrências de incêndios em vegetação ocorridos no estado do Ceará e avaliar a existência de uma relação entre a variabilidade do clima e a ocorrência desses eventos nessas regiões, visando identificar o período de maior ocorrência das queimadas, bem como entender como a questão cultural influencia no surgimento dos focos de incêndios em vegetação nessa região.

\subsection{Aspectos geográficos e climáticos do Estado do Ceará}

O estado do Ceará é uma das 27 unidades federativas, contido da Região Nordeste do Brasil, possui terri- tório de 148.825,6 km 2 e 184 municípios, tendo limites geográficos com o estado de Pernambuco ao Sul, o Oceano Atlântico ao Norte, com o s estado s do Rio Grande do Norte e da Paraíba a Leste e com o Piauí ao Oeste (Fig. 1a). Atualmente é dividido em sete mesorregiões: Noroeste, Norte, Região Metropolitana de Fortaleza (capital), Sertões Cearense, Jaguaribe, Centro - Sul e Sul, conforme classificação do Instituto de Pesquisa e Estratégia Econômica do Ceará - IPECE, mostrados na Fig. $1 b$.

O Ceará apresenta geografia física com predomínio de longas superfícies aplainadas de solos rasos e montes rochosos, suscetíveis a desertificação (Brandão, 2014), fenômeno que afeta toda a região semiárida do nordeste do Brasil, região também denominada de "Polígono das secas" (Brasil, 2016).

Ressalta-se que a desertificação é um processo irreversível da perda da cobertura vegetal, ocorre por processos naturais e/ou artificiais, sendo agravado pela ação do homem, pelo desmatamento e métodos inadequados de mineração ou agricultura. Em relação ao manuseio errado do solo na agricultura, evidencia-se, em especial, ênfase ao uso do fogo em queimadas da vegetação como forma de limpeza e preparação do solo a ser cultivado. O Mapa da Fig. 1c mostra as áreas suscetíveis a desertificação no Ceará.

Em relação a climatologia das chuvas observada na região, tem-se bem definido um período chuvoso nos meses de fevereiro a maio de cada ano, como chuvas médias de aproximadamente $800 \mathrm{~mm}$ (Fonte: Fundação Cearense de Meteorologia e Recursos Hídricos - FUNCEME), tendo a Zona de Convergência Intertropical (ZCIT) como principal sistema meteorológico causador de chuvas nesse período (Alves e Repelli, 1992; Alves,
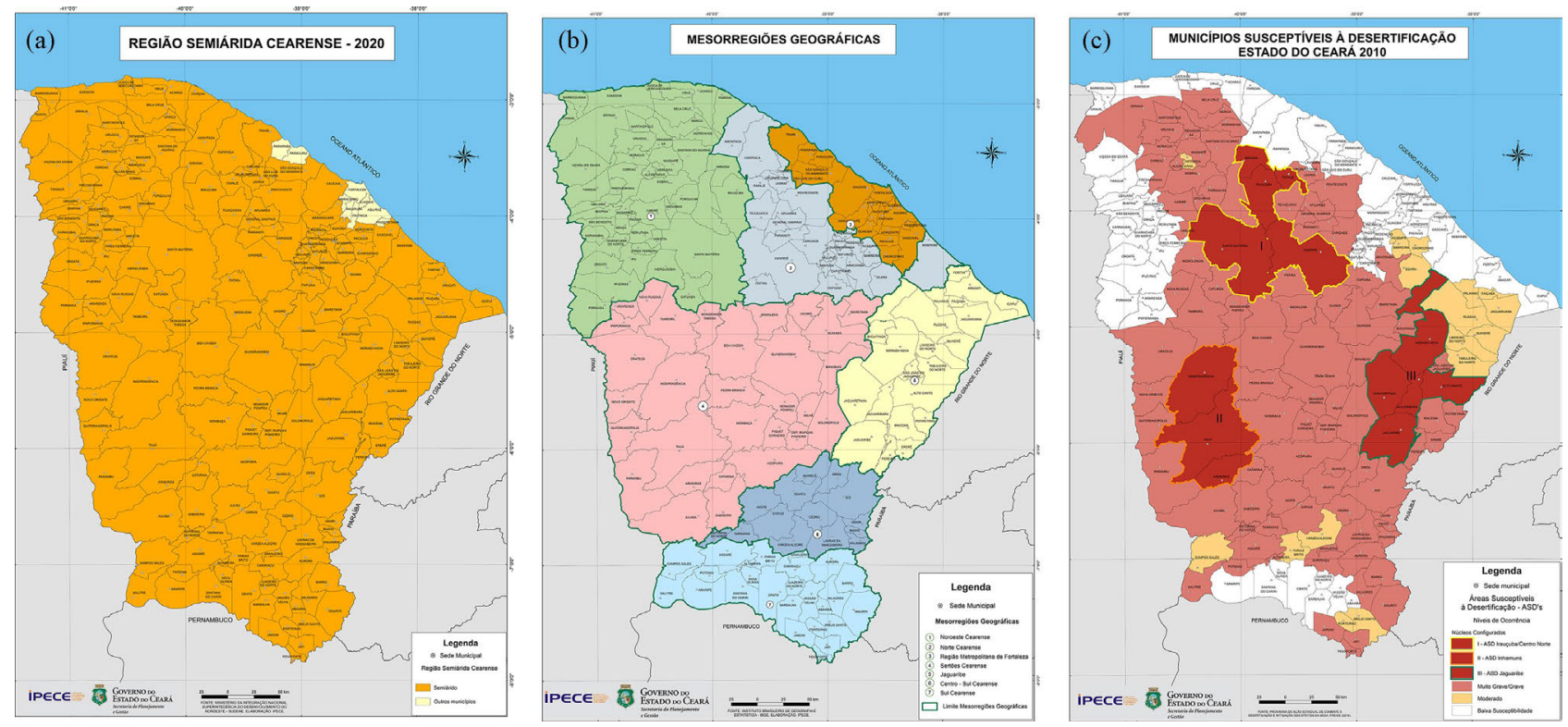

Figura 1 - Mapas do Ceará, (a) limites com estados e delimitação dos municípios contidos na região semiárida do nordeste brasileiro, (b) mesorregiões de interesse econômico e (c) munícipios susceptíveis à desertificação. Fonte: IPECE (2020). 
2017), e um período de pré-estação chuvosa entre os meses de dezembro e janeiro (Suliano et al., 2009). Na Fig. 2 são mostrados os totais médios anuais para o período em estudo e a distribuição espacial das chuvas observadas nesse período no Ceará.

Menciona-se a existência de uma grande variabilidade espaço-temporal das chuvas observadas nessa região, com a observação de períodos denominados de veranicos, períodos sem a ocorrência de chuvas no período quadra chuvosa (Silva et al., 2011; Muniz et al., 2017).

Em relação as ocorrências de secas ou períodos chuvosos com chuvas abaixo da média climatológica, ou ainda ausência de chuvas no período chuvoso nessa região, Campos (2014) descreve as observações, nessa região, de seca hidrológica que significa pouca ou nenhuma acumulação de águas nos açudes, e de seca agrícola que significa chuvas insuficientes ou com distribuição no tempo e no espaço de forma prejudicial à lavoura, que também é denominada de seca verde.

\subsection{Aspectos culturais presentes na prática das queimadas e do fogo em vegetação}

Castro (2012) cita que no nordeste brasileiro, e em particular na região semiárida, onde estão $95 \%$ dos municípios cearenses (Fig. 1a), encontra-se $82,6 \%$ da mão de obra do campo voltada para a agricultura familiar, mesmo com todos os problemas estruturais e processos de desertificação observados nessa região.

Ainda segundo Castro (2012) a metade dessa população não utiliza práticas recomendadas de agricultura e aproximadamente $25 \%$ das 170 mil famílias existentes nessa região usam o fogo controlado na vegetação como prática de limpeza do terreno para fins agrícolas.

Alguns autores afirmam que atear fogo na vegetação de forma controlada é um meio de o manejo da terra, além de servir para abrir espaço na mata nativa, eliminar restos de desmatamento e de lavouras pré-existentes bem com prepara o terreno para novo plantio ou para a atividade (a)

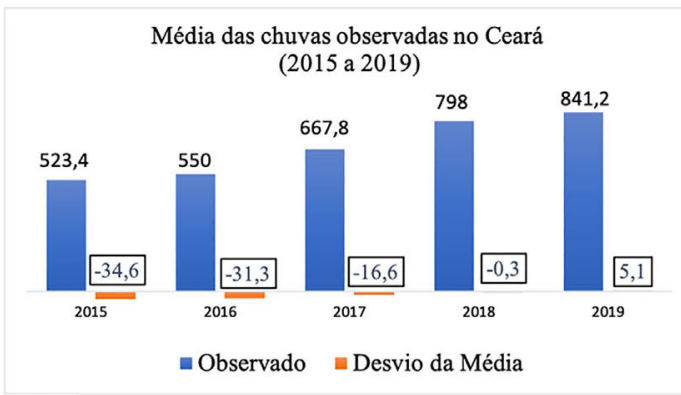

(b)

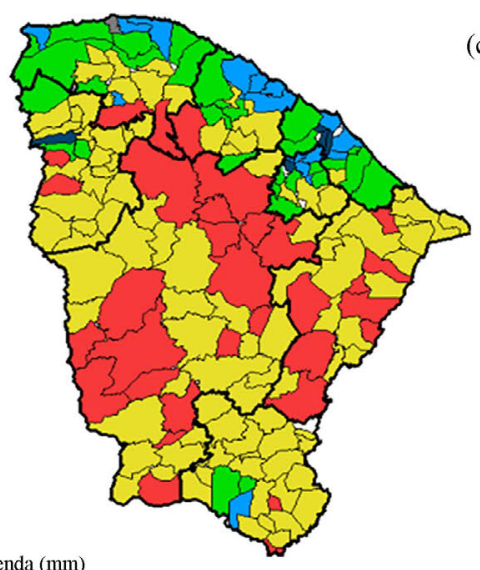

Acima de 1600.0 De 700.1 a 1000 De 0 a 200.0 (c)

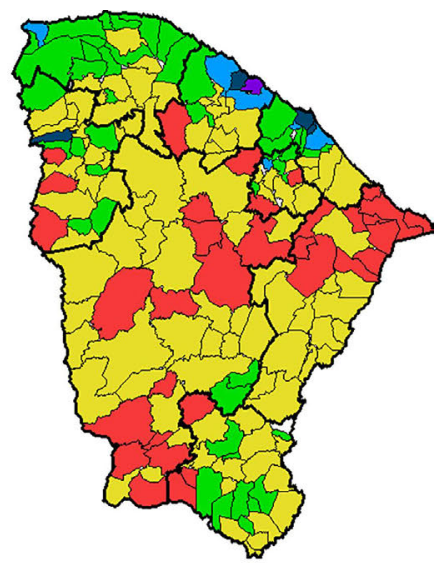

(d)

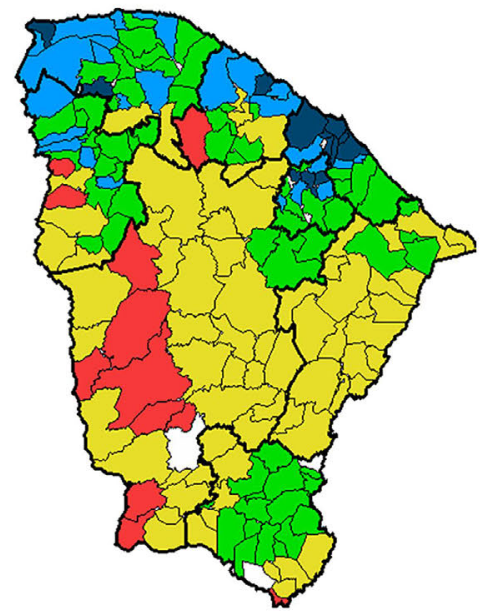

(e)

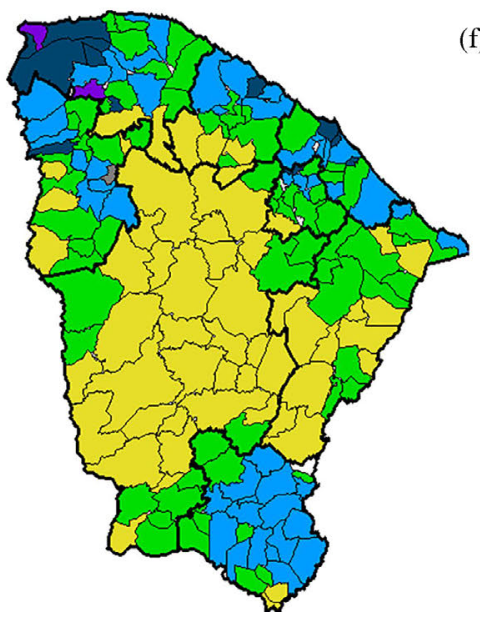

(f)

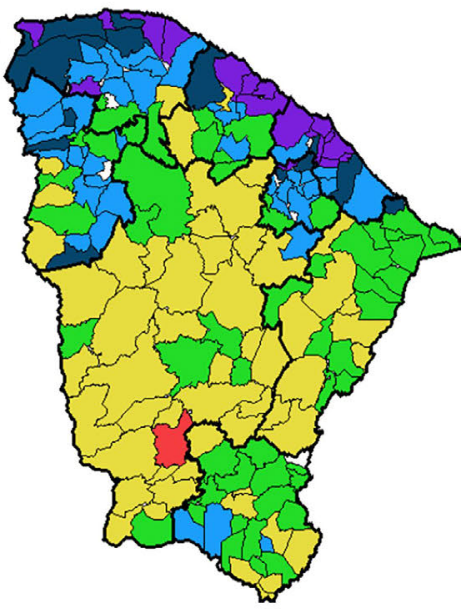

Figura 2 - (a) Média das chuvas observadas no Ceará de 2015 a 2019, (b) chuvas observadas por municípios em 2015, (c) em 2016, (d) em 2017, (e) em 2018 e (f) em 2019. Fonte: FUNCEME (2020). 
pecuária. Ainda afirmam que essa prática pode trazer alguns benefícios, tais como a eliminação de pragas e o fornecimento de nutrientes decorrente das cinzas, além de ser rápida e de baixo custo (Ribeiro, 1997; Bonfim; 2001; Gonçalves, 2005).

A queimada (sem controle) da vegetação é originária do cultivo indígena, porém era feita de forma extremamente cuidadosa e em locais restritos. Com a chegada da colonização europeia, o método passou a ser usado de forma indiscriminada, principalmente após a adoção dos grandes latifúndios coloniais de exportação. Nesse período difundiu -se a visão de que a natureza estava ali para servir, uma fonte inesgotável de recursos naturais, e daí se iniciou o processo de devastação das matas, inicialmente as litorâneas, com o uso do fogo e outras técnicas danosas ao meio ambiente (Leonel, 2000).

No Ceará as queimadas nas comunidades agrícolas são observadas, em geral, no período da pré-estação (dezembro e janeiro) chuvosa e/ou nos meses que a antecedem. Historicamente, os meses de outubro e novembro se caracterizaram como os de elevado índice de queimadas, afirmando a questão cultural de limpar o terreno com fogo para as práticas agrícolas e pecuárias. Apesar de existirem vários programas do governo, através das Coordenadoria Estadual de Defesa Civil do Corpo de Bombeiros Militares do Ceará (CEDEC-CE), para a conscientização do uso do solo e consequentemente dos problemas (incêndios) associados as queimadas de vegetação nessa região.

\section{Metodologia}

Os registros das ocorrências de incêndios em vegetação e os dados climatológicos de precipitação pluviométrica (chuvas) no Ceará, no período de 2015 a 2019, são provenientes de duas fontes de dados, respectivamente, da Coordenadoria Integrada de Operações de Segurança (CIOPS), através do Corpo de Bombeiros Militar do Estado do Ceará (CBMCE), e da Fundação Cearense de Meteorologia e Recursos Hídricos (FUNCEME).

Assim, foram construídos gráficos e tabelas com objetivo de quantificar e definir o período de maior ocorrência dos focos de incêndios em vegetação na região e no período em estudo, e para a construção de uma reflexão crítica sobre os impactos ambientais e socioeconômicos relacionados a ocorrência desses incêndios em vegetação no Ceará.

\section{Resultados e Discussões}

Na Tabela 1 apresenta -se os registros de ocorrência de incêndio em vegetação realizados através de ligações da comunidade para a CIOPS e compilados pelo setor de estatística da Secretaria da Segurança Pública e Defesa Social (SSPDS) do Estado do Ceará.
Tabela 1 - Registros das ocorrências de incêndios em vegetação da CIOPS-CE.

\begin{tabular}{lccccc}
\hline Mês/ano & 2015 & 2016 & 2017 & 2018 & 2019 \\
\hline Janeiro & 185 & 112 & 136 & 201 & 71 \\
Fevereiro & 124 & 62 & 48 & 28 & 17 \\
Março & 19 & 81 & 10 & 37 & 5 \\
Abril & 8 & 30 & 24 & 16 & 9 \\
Maio & 40 & 75 & 33 & 29 & 35 \\
junho & 77 & 314 & 106 & 174 & 125 \\
Julho & 153 & 699 & 231 & 318 & 236 \\
Agosto & 631 & 951 & 592 & 720 & 944 \\
Setembro & 698 & 841 & 933 & 1023 & 1048 \\
Outubro & 932 & 1025 & 725 & 959 & 1187 \\
Novembro & 751 & 796 & 601 & 955 & 1071 \\
Dezembro & 614 & 484 & 437 & 185 & 745 \\
Total & $\mathbf{4 . 2 3 2}$ & $\mathbf{5 . 4 7 0}$ & $\mathbf{3 . 8 7 6}$ & $\mathbf{4 . 6 4 5}$ & $\mathbf{5 . 4 9 3}$ \\
\hline Fone: CIOPS-SSPD/CE & & & &
\end{tabular}

Fonte: CIOPS-SSPDS/CE.

Os resultados mostram que foram registradas as ocorrências de incêndios em vegetação entre os meses de janeiro de 2015 a dezembro de 2019. Nesse período são observados registros totais de 4.232 focos de incêndios em 2015, 5.470 em 2016, 3.876 em 2017, 4.645 em 2018 e $5.493 \mathrm{em} 2019$.

Esse alto número de ocorrência de incêndios no Ceará em 2019 encontra explicação na combinação de altas temperatura e baixa umidade relativa do ar, com alta intensidade dos ventos, fatores que contribuíram para o elevado número de incêndios nessas regiões (FUNCEME, 2020).

Nesse contexto, Feitosa (2019) menciona em matéria jornalística que no segundo semestre de 2019 o estado do Ceará apresentou três entre os dez municípios com maior média de ventos observada no país (Acaraú, Jaguaruana e Campos Sales), com registros de rajadas que chegaram a $80 \mathrm{~km} / \mathrm{h}$.

Observa-se na Fig. 3 que no período em estudo (2015 a 2019) o maior de número de ocorrência de incêndios em vegetação no Ceará ocorre no segundo semestre de cada ano, entre os meses de julho a dezembro, sendo crescente as ocorrências com pico nos meses de setembro e outubro. Complementarmente, observam-se que no primeiro semestre, de janeiro a junho, encontram-se o menor número de ocorrência de incêndios dessa natureza no estado.

Ressalta-se que o comportamento da curva apresentada na representação gráfica da Fig. 3 se assemelha ao inverso da curva da climatologia do total mensal de precipitação pluviométrica (chuvas) observada para o estado do Ceará, ou seja, quando no primeiro semestre do ano em que tem-se o período de maior ocorrência das chuvas na região encontram-se o menor número de ocorrência dos incêndios em vegetação, e no segundo semestre, enquanto 


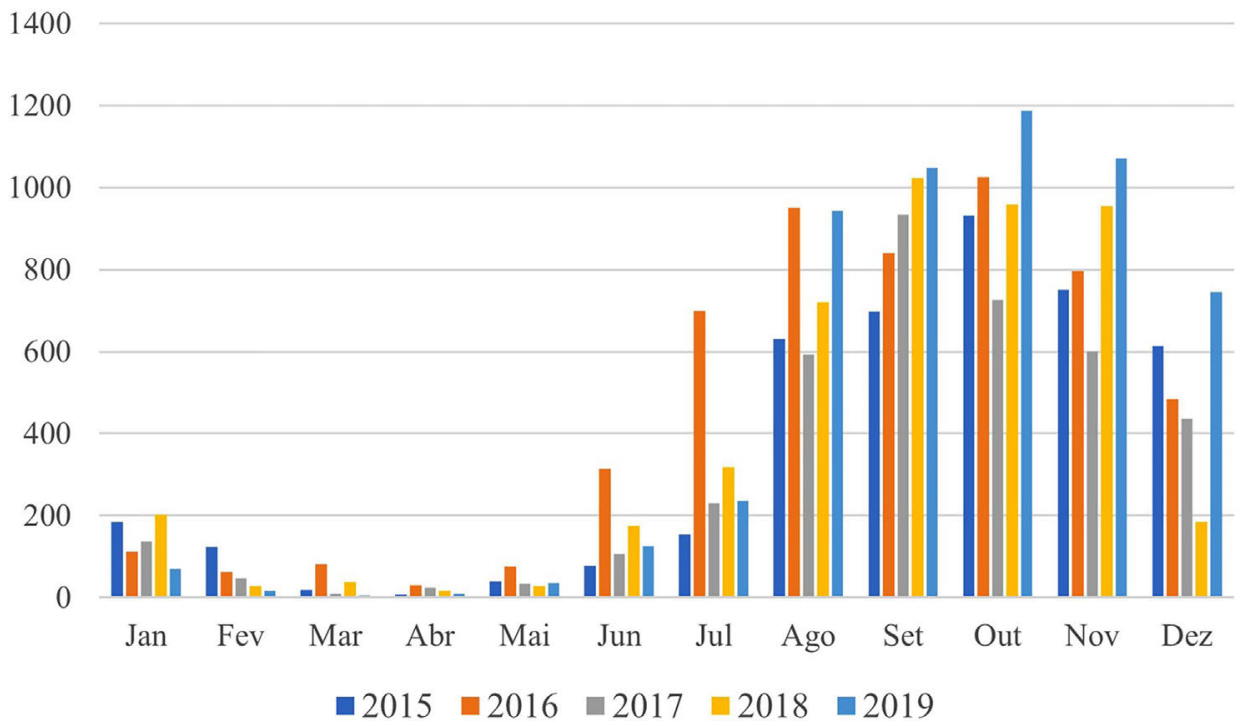

Figura 3 - Ocorrências de incêndio em vegetação (2015 a 2019). Fonte: CIOPS-SSPDS/CE.

observa-se o período seco da região, tem-se o maior número de ocorrências de incêndio em vegetação na região.

Na Fig. 4 encontra-se a relação entre o número médio de ocorrências de incêndios em vegetação, registrados no banco de dados da CIOPS -SSPDS/CE, e os totais médios climatológicos das chuvas mensais observadas no Ceará. Os resultados mostram que, no período mais úmido, correspondente aos meses de janeiro a junho, registrou-se menor número de incêndios em vegetação, ou seja, tem-se que no primeiro semestre do ano ocorrem aproximadamente $92 \%$ das chuvas anuais e cerca de $11,2 \%$ das ocorrências de incêndios em vegetação no estado. Situação inversa a observada no segundo semestre em que ocorrem cerca de $8 \%$ das chuvas e $88,8 \%$ das ocorrências de incêndios em vegetação no Ceará.

Os registros das ocorrências de incêndios em vegetação obtidos no CIOPS-SSPDS/CE quando analisados em conjunto com os registros das chuvas médias mensais no Ceará obtidos na FUNCEME mostram concordância com os resultados publicados em estudos científicos citados anteriormente.

Nesse contexto, menciona-se que concordam com Pezzopane et al. (2001) na afirmativa de que os incêndios na região semiárida se concentram nas estações de primavera e inverno e que estão associados aos baixos índices de pluviometria observados na região. Concordam também com Sampaio (1991) na afirmativa de que a estação denominada como normal do fogo corresponde ao período do ano em que as variáveis climatológicas apresentam baixa precipitação pluviométrica e umidade relativa do ar.

Em adição, ressalta-se que a série temporal pesquisada retrata a sazonalidade das ocorrências de fogo em vegetação na região em estudo, quer sejam por ignição provocada pelo homem ou não, as ocorrências são predominantes nos meses de setembro, outubro, novembro e

\section{Percentual (\%) médio mensal de ocorrências de incêndio em vegetação (CIOPS) e a climatologia das chuvas observadas no Ceará (FUNCEME)}

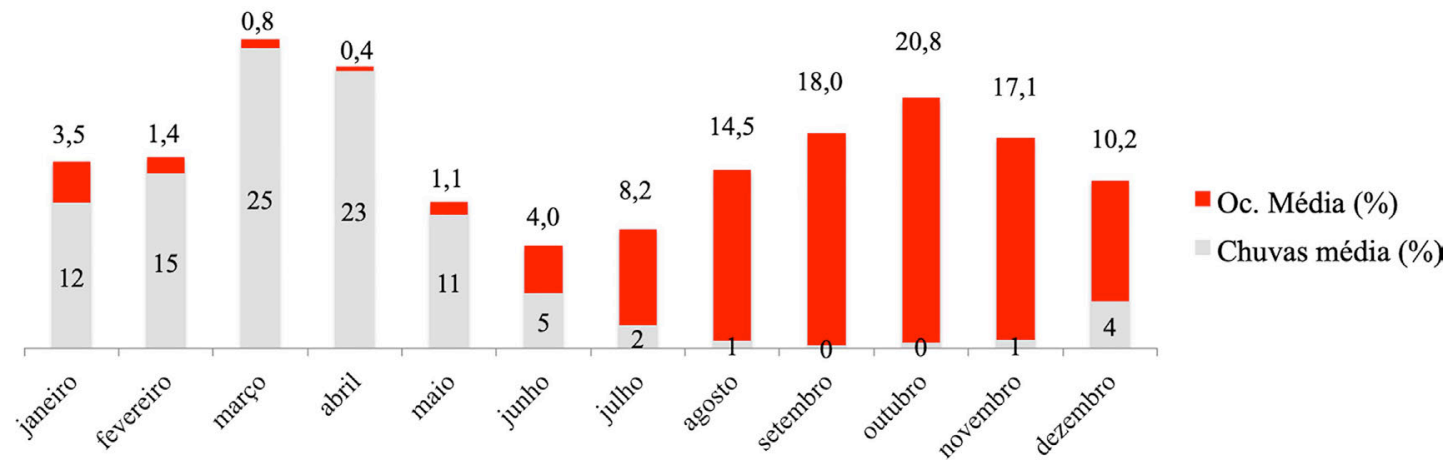

Figura 4 - Chuvas e registros de incêndios em vegetação no Ceará. Fonte: FUNCEME e CIOPS-CE. 
dezembro, e são consequência de uma série de fatores, antrópicos, culturais, meteorológicos e ambientais.

\section{Considerações Finais}

Ações antrópicas estão transformando o planeta (Terra) rapidamente e uma das mais severas agressões ao meio ambiente decorre da prática de atear fogo na vegetação, embora o fenômeno possa ocorrer de causas naturais, como raios, a quase totalidade dos eventos registrados ocorrem pela ação humana com o objetivo de preparar o solo para a plantação, de forma rápida, com baixo custo e de resultado satisfatório. Contudo, sem a preocupação com o meio ambiente, o fogo na vegetação (incêndios) pode proporcionar danos, tais como a eliminação de nutrientes orgânicos do solo que podem levar a desertificação da área a ser cultivada ou usada para a pecuária.

Os resultados apresentados nesse estudo mostram que existe uma relação entre a ocorrência de incêndios florestais, associados a prática de atear fogo na vegetação de forma não controlada, e as condições meteorológicas, ambientais e culturais das comunidades cearenses.

Assim, constatou -se que no período chuvoso da região em estudo (primeiro semestre do ano) têm-se os menores registros de ocorrências desses eventos, e que nos meses do segundo semestre, incluindo o período da préestação chuvosa da região, observam-se os maiores números de registros de queimadas da vegetação para fins agropecuários. Fato este que, potencializado pelo período de estiagem e de baixa umidade relativa do ar, combinado com a intensificação dos ventos, juntamente com condição da vegetação mais seca e suscetível, aumenta a probabilidade de incêndios florestais na região.

O conjunto de fatores reunidos propicia e de certa forma explica a grande quantidade de queimadas no período, fato que se repete ano a ano, com variação de algumas semanas, mas sempre no mesmo período, ou seja, o problema é sazonal e passível de mitigação por parte das autoridades competentes.

Por fim, deixa-se como recomendação para auxiliar nas rotinas de prevenção e mitigação dos efeitos e danos causados pela prática de atear fogo na vegetação de forma descontrolada, a realização de campanhas visando conscientizar as comunidades cearenses dos graves danos ambientais que podem ser causados por essa prática.

\section{Referências}

ALVES, J.M.B.; REPELLI, C.A. Variabilidade pluviométrica no setor norte do Nordeste e os eventos EI Niño - Oscilação Sul. Revista Brasileira de Meteorologia, v. 7, n. 2, p. 583$592,1992$.

ALVES, J.M.B.; SILVA, E.M.; RICKS, C.P. Dynamic downscaling of precipitation and dry spells in Ceará State. Journal of Environmental Analysis and Progress, v. 2, n. 4, p. 385-393, 2017.
BONFIM, V. R. Diagnóstico do Uso do Fogo no Entorno do Parque Estadual da Serra do Brigadeiro. Dissertação de Mestrado em Ciência Florestal, Universidade Federal de Viçosa, Viçosa, 55 p. 2001.

BRANDÃO, R.L.; FREITAS, L.C.B. Geodiversidade do Estado do Ceará - Programa Geologia do Brasil, Levantamento da Geodiversidade. Fortaleza: Serviço Geológico do Brasil, 2014.

BRASIL. Ceará: Inventário Florestal Nacional: Principais Resultados. Brasília: Ministério do Meio Ambiente, 2016.

CAMPOS, J.N.B. Secas e políticas públicas no Semiárido: Ideias, pensadores e períodos. Estudos Avançados, v. 28, n. 82, p. 65-88, 2014.

CASTRO, C.N. A Agricultura no Nordeste Brasileiro: Oportunidades e Limitações ao Desenvolvimento. Texto para Discussão. Rio de Janeiro: IPEA, 2012. Disponível em: http://repositorio.ipea.gov.br/bitstream/11058/1011/1/ TD_1786.pdf.

FEITOSĀ, A. Três municípios do Ceará estão entre os dez com maior média de ventos. Jornal O Povo, 2019, disponível em: https://www.opovo.com.br/noticias/ceara/2019/10/02/ tres-municipios-do-ceara-estao-entre-os-dez-com-maiormedia-de-ventos.html.

FIEDLER, N.C.; MERLO, A.M.; MEDEIROS, M.B. Ocorrência de incêndios florestais no Parque Nacional da Chapada dos Veadeiros, Goiás. Ciência Florestal, v. 16, n. 2, p. 153161, 2006.

GONÇALVES, J.S. A Prática da Queimada no Saber Tradicional e na Concepção Científica de Risco: Estudo sobre o Uso do Fogo Por Pequenos Produtores Rurais do Norte do Estado de Minas Gerais. Dissertação de Mestrado em Ciência Florestal, Universidade Federal de Viçosa, Viçosa, 2005.

IPECE. Ceará, Caracterização Territorial. Fortaleza: Instituto de Pesquisa e Estratégia Econômica do Ceará, 2012. Disponível em: http://www2.ipece.ce.gov.br/publicacoes/cear a_em_numeros/2012/territorial/01_001_caracteristicas_ geograficas.pdf.

LEONEL, M. Bio-sociodiversidade: preservação e mercado. Estudos Avançados, v. 14, n. 38, p. 321-346, 2000.

MACEDO, W.; SARDINHA, A.M. Fogos Florestais. Vila Real: Universidade de Trás-os Montes e Alto Douro, 430 p., 1985.

MEDEIROS, M.B.; FIEDLER, N.C. Incêndios florestais no parque da Serra da Canastra: desafios para a conservação da biodiversidade. Ciência Florestal, v. 14, n. 2, p. 157-168, 2004.

MUNIZ, L.F.; PEREIRA, J.M.R.; XIMENES JUNIOR, C.L.; STUDAR, T.M.C. Classificação climática para o Estado do Ceará, utilizando distintos sistemas de caracterização. Congresso da Associação Brasileira de Recursos Hídricos - ABRH, Florianópolis, 2017. Disponível em: https:// s3-sa-east-1.amazonaws.com/abrh/Eventos/Trabalhos/60/ PAP022393.pdf.

PRADO, D.E. As Caatingas da América do Sul. Ecologia e Conservação da Caatinga. Recife: Ed. Universitária da UFPE, p. 3-73, 2003.

PEZZOPANE, J.E.M.; OLIVEIRA NETO, S.N.; VILELA, M.F. Risco de incêndio em função da característica do clima, relevo e cobertura do solo. Floresta e Ambiente, v. 8, n. 1, p. 167-166, 2001. 
PRUDENTE, T.D. Geotecnologia Aplicada ao Mapeamento de Risco de Incêndios Florestal no Parque Nacional da Chapada dos Veadeiros e Área de Entorna. Dissertação de Mestrado, Universidade Federal de Uberlândia, Uberlândia, 2010.

RIBEIRO, G.A. Estudo do Comportamento do Fogo de Alguns Efeitos da Queima Controlada em Povoamento de Eucaliptus viminolis Labil em Três Barras, Santa Catarina. Tese de Doutorado em Ciência Florestal, Universidade Federal do Paraná, Londrina, 145 p., 1997.

SAMPAIO, O.B. Estudo Comparativo de Índices, para Previsão de Incêndios Florestais, na Região de Coronel Fabriciano, Minas Gerais. Dissertação de Mestrado em Ciência Florestal, Universidade Federal de Viçosa, Viçosa, 88 p., 1991.

SILVA, V.P.R.; PEREIRA, E.R.R.; AZEVEDO, P.V.; SOUSA, F.A.S.; SOUSA, I.F. Análise da pluviometria e dias chuvosos na região Nordeste do Brasil. Revista Brasileira de Engenharia Agrícola e Ambiental, v. 15, n. 2, p. 131-138, 2011.

SILVA, J.C.; FLIEDER, N.C.; RIBEIRO, G.A.; SILVA JUNIOR, M.C. Avaliação de brigadas de incêndios florestais em uni- dades de conservação. Revista Árvore, v. 27, n. 1, p. 95101, 2003.

SOARES, R.V. Queimas controladas: Pós e Contras. Fórum Nacional Sobre Incêndios Florestais. Piracicaba: Anais IPEF, p. 6-10, 1995.

SUliANO, D.C.; MAGALHÃES, K.A.; SOARES, R.B. A influência do Clima no Desempenho da Economia Cearense. Fortaleza: Instituto de Pesquisa e Estratégia Econômica do Ceará, 2009. Disponível em: https://www.ipece. ce.gov.br/wp-content/uploads/sites/45/2014/02/TD_56.pdf.

TORRES, F.T.P.; RIBEIRO, G.A. Índices de risco de incêndios florestais em Juiz de Fora/MG. Seropédica: Floresta e Ambiente, v. 15, n. 2, p. 30-39, 2008.

\section{Endereços de Internet}

FUNCEME. www.funceme.br. IPECE. www.ipece.ce.gov.br.

License information: This is an open-access article distributed under the terms of the Creative Commons Attribution License (type CC-BY), which permits unrestricted use, distribution and reproduction in any medium, provided the original article is properly cited. 